\title{
Proteomic Profiling of Archived Tissue of Primary Melanoma Identifies Proteins Associated with Metastasis
}

\author{
Andrew Shapanis ${ }^{1}\left({ }^{\circ}\right.$, Chester Lai $^{2,3}{ }^{(0)}$, Mathew Sommerlad ${ }^{4}$, Erika Parkinson ${ }^{1}$, \\ Eugene Healy $2,3,+\left(\mathbb{D}\right.$ and Paul Skipp ${ }^{1, *,+}$ \\ 1 Centre for Proteomic Research, Biological Sciences, University of Southampton, Southampton SO17 1BJ, UK; \\ andy.shapanis@soton.ac.uk (A.S.); E.P.Parkinson@soton.ac.uk (E.P.) \\ 2 Dermatopharmacology, Clinical and Experimental Sciences, Faculty of Medicine, University of \\ Southampton, Southampton SO166YD, UK; C.Y.Lai@soton.ac.uk (C.L.); E.Healy@soton.ac.uk (E.H.) \\ 3 Dermatology, University Hospital Southampton NHS Foundation Trust, Southampton SO16 6YD, UK \\ 4 Histopathology, University Hospital Southampton NHS Foundation Trust, Southampton SO16 6YD, UK; \\ mathew.sommerlad@uhs.nhs.uk \\ * Correspondence: pjss@soton.ac.uk \\ + These authors are joint senior authors.
}

Received: 28 September 2020; Accepted: 30 October 2020; Published: 31 October 2020

\begin{abstract}
Formalin-fixed paraffin embedded (FFPE) clinical tissues represent an abundant and unique resource for translational proteomic studies. In the US, melanoma is the 5th and 6th most common cancer in men and women, respectively, affecting over 230,000 people annually and metastasising in $5-15 \%$ of cases. Median survival time for distant metastatic melanoma is 6-9 months with a 5-year-survival of $<15 \%$. In this study, 24 primary FFPE tumours which have metastasised (P-M) and 24 primary FFPE tumours which did not metastasise (P-NM) were subjected to proteomic profiling. In total, 2750 proteins were identified, of which 16 were significantly differentially expressed. Analysis of TCGA data demonstrated that expression of the genes encoding for 6 of these 16 proteins had a significant effect on survival in cutaneous melanoma. Pathway analysis of the proteomics data revealed mechanisms likely involved in the process of melanoma metastasis, including cytoskeleton rearrangement, extracellular changes and immune system alterations. A machine learning prediction model scoring an AUC of 0.922, based on these 16 differentially expressed proteins was able to accurately classify samples into P-M and P-NM. This study has identified potential biomarkers and key processes relating to melanoma metastasis using archived clinical samples, providing a basis for future studies in larger cohorts.
\end{abstract}

Keywords: proteomics; melanoma; metastasis; FFPE; formalin fixed paraffin embedded

\section{Introduction}

Clinical tissue samples can be preserved in formaldehyde, embedded in paraffin wax, and stored at room temperature indefinitely without significant degradation occurring. This has resulted in huge biobanks of archived samples, frequently along with retrospective clinical information of a disease for which the clinical outcome and therapy responses are known, thus representing a valuable resource for biomarker discovery and the molecular profiling of disease pathways [1,2]. The practical utility of using formalin-fixed paraffin embedded (FFPE) samples for proteomic studies has previously been hampered by the adverse effects of formaldehyde fixation, making the efficient extraction of proteins a challenge. During the FFPE process, samples are incubated in formaldehyde for many hours resulting in the ubiquitous formation of cross linkages, most notably between primary amines. Unlike fresh/frozen 
samples, which are relatively straight forward to process, FFPE samples require additional steps to reduce these cross-linkages and enable downstream analysis. However, recent advances in Mass spectrometry (MS)-based proteomic methods now allow in-depth proteomic analysis of FFPE tissues [3]. The availability of this unique resource has motivated us to perform a proteomic analysis of primary melanoma in relation to the development of subsequent metastases using FFPE archived primary melanoma tumour samples in combination with their associated clinical outcome data.

Globally, cutaneous melanoma is thought to account for $1.7 \%(232,100)$ of all newly diagnosed cases of primary malignant cancers and $0.7 \%$ of all cancer deaths each year [4]. The incidence of melanoma differs widely amongst countries, with New Zealand and Australia having the highest rate at 35.8 per 100,000 person-years and 34.9 per 100,000 person-years, respectively [5]. The mortality rate of those in high risk countries like New Zealand and Australia is also elevated, with observed rates at 4.7 per 100,000 person-years and 4.0 per 100,000 person-years, respectively [5].

Melanoma metastasis is considered to occur in $5-15 \%$ of all melanoma cases [6-8], with one study of $>3000$ patients reporting that $15.5 \%$ of all melanomas progressed to metastatic melanoma and that $57.3 \%$ of all patients who developed distant metastasis died at the time of reporting [8]. The risk of mortality is directly associated with metastasis since 5-year survival rates for distant metastatic melanoma are as low as $15 \%$, with a median survival of $6-9$ months $[9,10]$.

Much of the current literature regarding melanoma metastasis focuses on comparisons of primary tumours and their metastases. Although a few studies have investigated FFPE melanoma samples using proteomics [11-13], to our knowledge, there have been no investigations comparing primary melanomas that have metastasised with primary melanomas that have not metastasised, a comparison which could help to inform on proteins and mechanisms involved in the progression to metastatic melanoma.

In this study, we have used global proteomic profiling of primary melanoma tumours, which had either metastasised or not metastasised, to identify potential biomarkers and possible mechanisms relating to the development of melanoma metastasis. These results highlight several key molecular processes which are likely involved in melanoma metastasis with a panel of proteins identified that could potentially be used to predict metastasis in unknown tumours.

\section{Results}

We compared the proteomic profiles of primary melanomas which had metastasised (P-M) with primary melanomas that had not metastasised (P-NM). A total of 48 samples were used, 24 in each group (P-M and P-NM) (Figure 1A). There were marginally more males in the P-M group compared to the P-NM group. The majority of melanomas in both P-M and P-NM groups were superficial spreading melanoma and Clark's level IV. Samples were stratified for Breslow thickness and showed no significant difference between the two groups.

In total, 2750 proteins were identified from the 48 FFPE samples, with 16 of these proteins (listed in the volcano plot, Figure 1B) identified as significantly differentially expressed between P-M and P-NM. Dot plots for the individual tumour expression of each of these 16 significantly differentially expressed proteins are shown in Figure 2.

Two datasets from the National Center for Biotechnology Information's Gene Expression Omnibus (NCBI GEO, datasets; GSE15605 and GSE46517) were used to validate these significantly differentially expressed proteins. Genes; Staphylococcal nuclease domain-containing protein 1 (SND1), Keratin 9 (KRT9), Histone H2A type 3 (HIST3H2A), Myosin-9 (MYH9) and Actin Gamma 1 (ACTG1) were significantly differentially expressed between PM and PNM in these data sets. Furthermore, to determine whether these significantly differentially expressed proteins that were associated with the development of metastases from primary melanoma were associated with a poorer clinical outcome, survival analysis of the cutaneous melanoma cohort from The Cancer Genome Atlas (TCGA) was performed. This analysis identified that expression of the genes encoding for 6 of the 16 significantly differentially expressed proteins were associated with reduced survival over a 3-year period (Figure 3); 
these comprised Envoplakin (EVPL), Periostin (POSTN), KRT9, MYH9, myosin heavy chain 16 (MYH16) and Phosphatidylethanolamine-binding protein 1 (PEBP1).

\begin{tabular}{l|cc}
\hline & & \\
\hline & P-M & P-NM \\
\hline Number of Samples & 24 & 24 \\
Male & 14 & 9 \\
& $(58.3 \%)$ & $(37.5 \%)$ \\
Female & 10 & 15 \\
& $(41.7 \%)$ & $(62.5 \%)$ \\
Superficial spreading & 17 & 20 \\
& $(70.8 \%)$ & $(83.3 \%)$ \\
Nodular & 6 & 4 \\
& $(25 \%)$ & $(16.7 \%)$ \\
Desmoplastic & 1 & 0 \\
& $(4.2 \%)$ & $(0 \%)$ \\
Clark's Level V & 2 & 0 \\
Clark's Level IV & $(8.3 \%)$ & $(0 \%)$ \\
Clark's Level $\leq$ III & 16 & 15 \\
Breslow & $(66.7 \%)$ & $(62.5 \%)$ \\
\hline
\end{tabular}

B

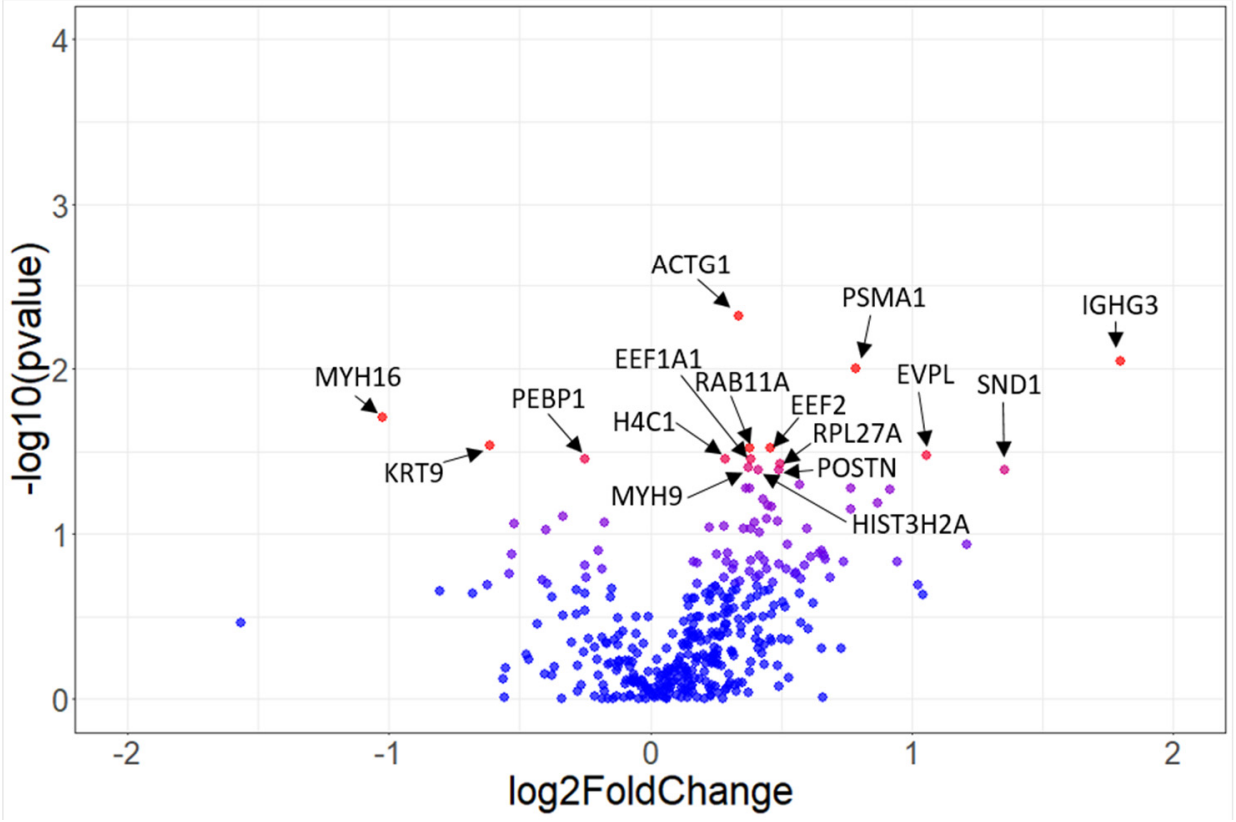

Figure 1. Proteomic analysis of primary melanomas which had metastasised (P-M) and those which had not metastasised (P-NM) reveals 16 significantly differentially expressed proteins. (A) clinical characteristics of P-M and P-NM samples. (B) Volcano plot of proteomic data. Pvalues were obtained by Mann-Whitney $\mathrm{U}$ test and fold changes by dividing the mean of each P-M protein by the mean of the P-NM protein. Blue $=p>0.05$, red $=p<0.05$. 

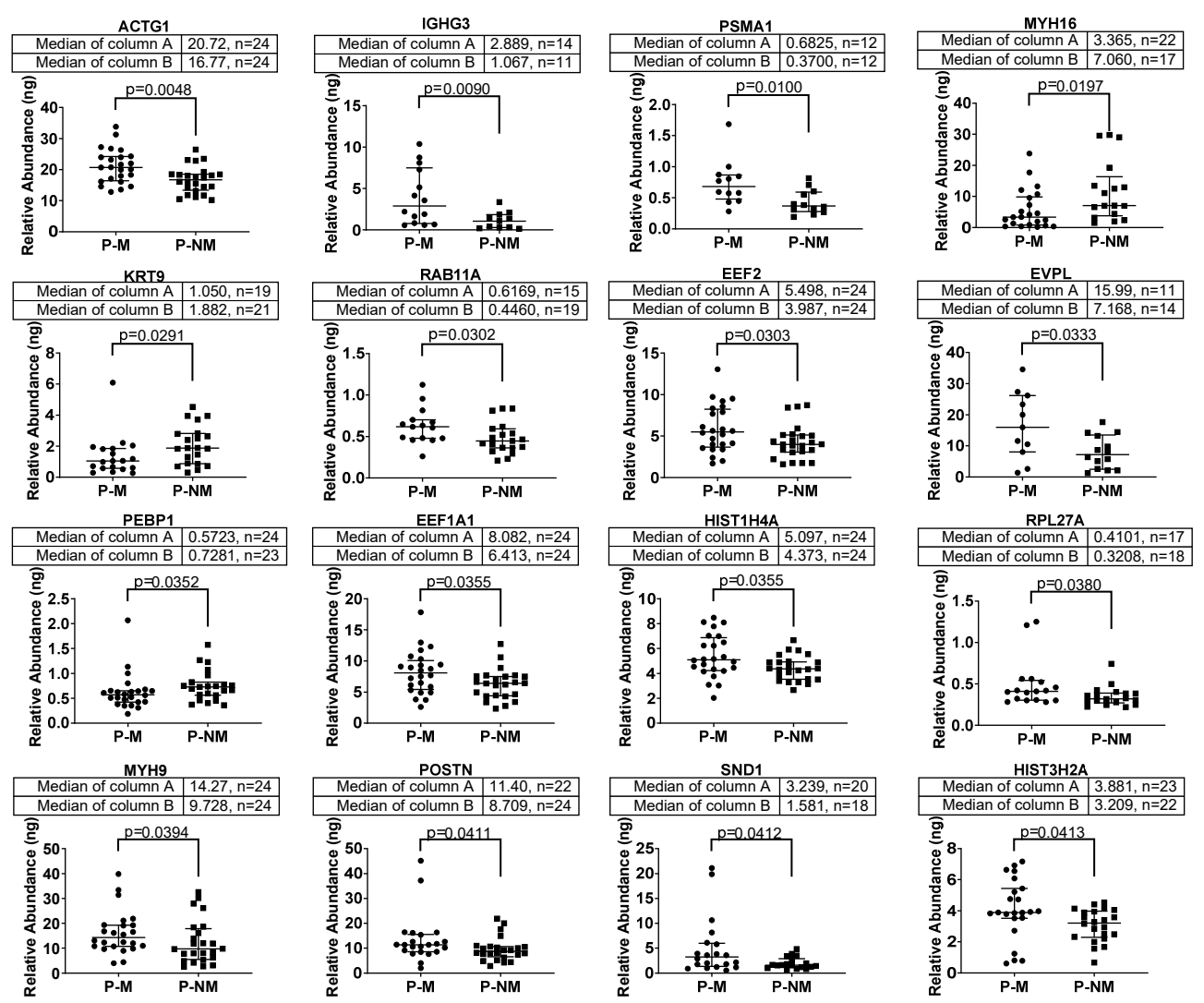

Figure 2. Dot plots showing individual tumour level of expression for each of the 16 significantly differentially expressed proteins in P-M and P-NM melanomas. Expression data for each protein were plotted using Prism, V8 (Graphpad, San Diego, CA, USA).

Protein network analysis of the significantly differentially expressed proteins was performed using STRING, v11 (Figure 4A). Using the STRING clustering function, four distinct clusters were identified, with the main clusters consisting of functions associated with translational and structural components. Functional and enrichment analyses of the significantly differentially expressed proteins were performed using G:Profiler. These revealed that these proteins were enriched in biological processes and molecular functions associated with the Mitogen-activated protein kinase (MAPK) pathway, translation/protein synthesis, and a range of binding functions (including intracellular and cell-to-cell) (Figure 4B,C). The most enriched ontologies in the Gene Ontology cellular compartment analysis were extracellular space, cytoskeletal and vesicles.

Ingenuity pathway analysis (IPA) of all unique proteins identified within at least $50 \%$ of samples, along with their $p$ values and fold changes, reflected the gene ontology enrichment analysis (Figure 5), highlighting translation/protein synthesis (EIF2 signalling), cytoskeletal remodelling (epithelial adherens junctions, actin cytoskeleton signalling) and extracellular signalling (Integrin-linked kinase, ILK) as enriched processes. Activation of the signalling pathways associated with acute phase response, granzyme B, IL15, the upstream modulator, HSP90B1 and inhibition of the upstream modulator EOMES also indicated immune related mechanisms in development of melanoma metastasis. Other interesting areas of enrichment included activation and inhibition of upstream hypoxia associated proteins including Hypoxia-inducible factor 1-alpha (HIF1a) and egl-9 family hypoxia inducible factor 1 $(E G L N)$, respectively. 
a
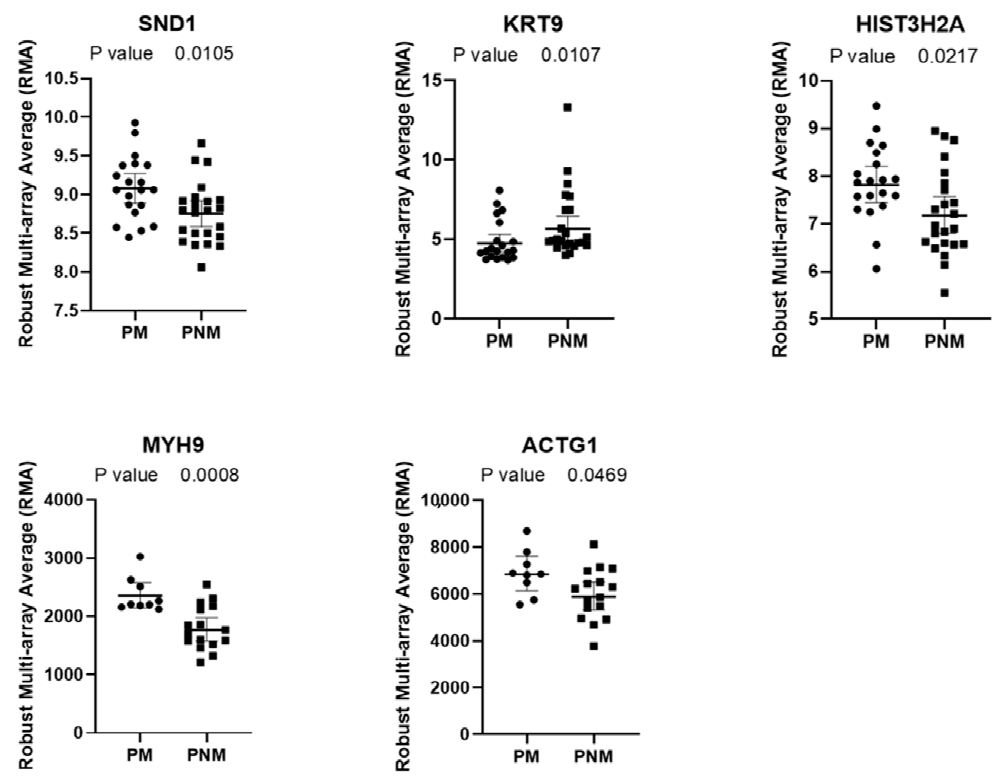

b
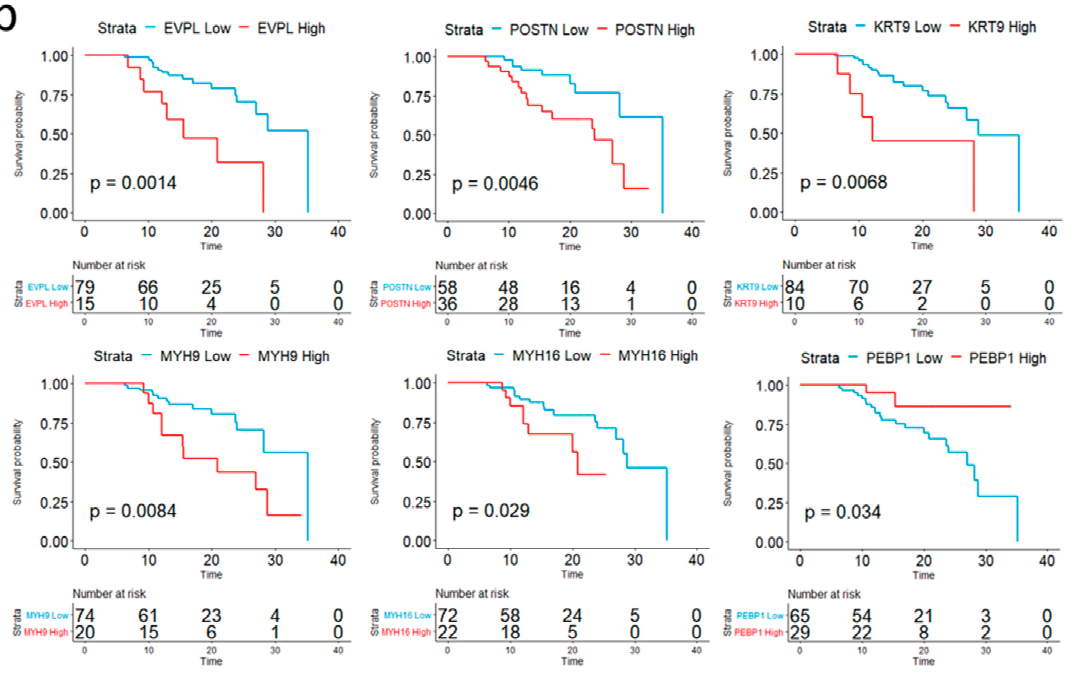

Figure 3. Validation of differentially expressed proteins using two NCBI GEO datasets and TCGA survival analysis. (a) Primary melanoma samples which could be inferred as either P-M or P-NM from GEO datasets; GSE15605 and GSE46517, were analysed separately for the 16 differentially expressed proteins identified via mass spectrometry. Median with interquartile range shown as error bars. (b) Survival analysis of cutaneous melanoma data from TCGA indicated that genes encoding for 6 proteins that were significantly differentially between P-M and P-NM have a significant effect on 3-year survival in patients with cutaneous melanoma.

A Distance Weighted Discrimination with a Radial Basis Function Kernel machine learning model was used to create a predictive model based upon the 16 significantly differentially expressed proteins to classify samples as either P-M or P-NM. Figure 6 shows the area under the Receiver Operating Characteristic (ROC) curve, correctly classifying P-M samples with excellent performance (AUC $=0.922$ ). There were two optimal thresholds (that is the threshold that achieved the highest sum sensitivity/specificity). The first achieved a sensitivity of $75 \%$ and specificity of $100 \%$, the second achieved a sensitivity and specificity of $88 \%$. This model highlights the potential predictive power of these proteins, but warrants further investigation in a larger independent cohort. 
A

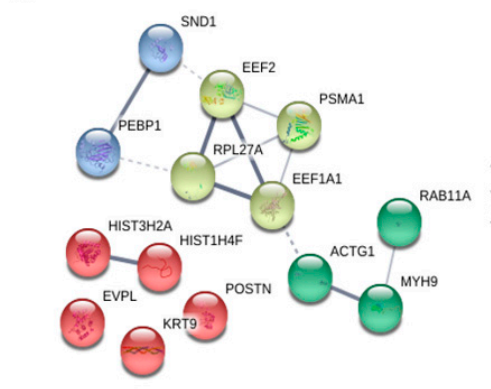

B

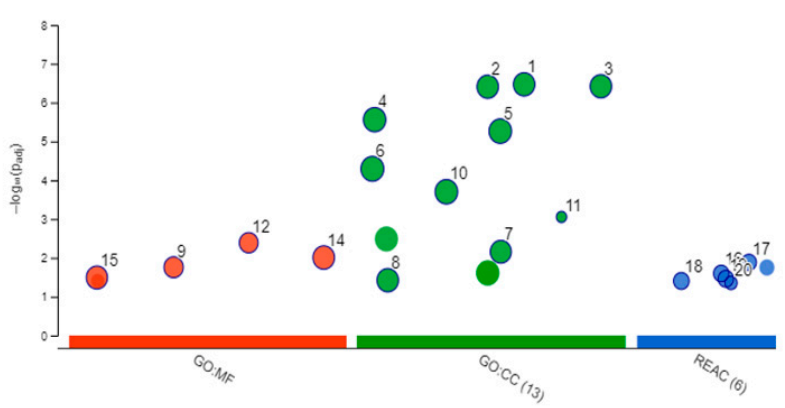

C

\begin{tabular}{|c|c|c|c|c|c|c|}
\hline ID & source & term name & term size & ze & ze & p value \\
\hline 1 & $\overline{\mathrm{GO}: \mathrm{CC}}$ & extracellular exosome & 2143 & 13 & 11 & $3.4 \times 10^{-7}$ \\
\hline 2 & $\mathrm{GO}: \mathrm{CC}$ & extracellular organelle & 2171 & 13 & 11 & $3.9 \times 10^{-7}$ \\
\hline 3 & GO:CC & extracellular vesicle & 2166 & 13 & 11 & $3.8 \times 10^{-7}$ \\
\hline 4 & $\mathrm{GO}: \mathrm{CC}$ & extracellular space & 3541 & 13 & 12 & $2.8 \times 10^{-6}$ \\
\hline 5 & $\mathrm{GO}: \mathrm{CC}$ & extracellular region part & 3751 & 13 & 12 & $5.4 \times 10^{-6}$ \\
\hline 6 & $\mathrm{GO}: \mathrm{CC}$ & extracellular region & 4536 & 13 & 12 & $5.1 \times 10^{-5}$ \\
\hline 7 & GO:CC & cytoskeletal part & 1707 & 13 & 7 & $7.0 \times 10^{-3}$ \\
\hline 8 & $\mathrm{GO}: \mathrm{CC}$ & cytoskeleton & 2221 & 13 & 7 & $3.8 \times 10^{-2}$ \\
\hline 9 & GO:MF & structural molecule activity & 680 & 13 & 5 & $1.8 \times 10^{-2}$ \\
\hline 10 & GO:CC & vesicle & 3891 & 13 & 11 & $2.0 \times 10^{-4}$ \\
\hline 11 & GO:CC & dense body & 6 & 13 & 2 & $8.8 \times 10^{-4}$ \\
\hline 12 & GO:MF & cell adhesion molecule binding & 502 & 13 & 5 & $4.1 \times 10^{-3}$ \\
\hline 13 & GO:MF & cadherin binding & 330 & 13 & 4 & $1.6 \times 10^{-2}$ \\
\hline 14 & GO:MF & carbohydrate derivative binding & 2256 & 13 & 8 & $9.8 \times 10^{-3}$ \\
\hline 15 & GO:MF & RNA binding & 1902 & 13 & 7 & $3.2 \times 10^{-2}$ \\
\hline 16 & REAC & Oncogenic MAPK signaling & 81 & 12 & 3 & $2.5 \times 10^{-2}$ \\
\hline 17 & REAC & Signaling by BRAF and RAF fusions & 65 & 12 & 3 & $1.3 \times 10^{-2}$ \\
\hline 18 & REAC & Eukaryotic Translation Elongation & 94 & 12 & 3 & $3.9 \times 10^{-2}$ \\
\hline 19 & REAC & Peptide chain elongation & 90 & 12 & 3 & $3.5 \times 10^{-2}$ \\
\hline 20 & REAC & Protein methylation & 17 & 12 & 2 & $4.4 \times 10^{-2}$ \\
\hline
\end{tabular}

Figure 4. Analysis of significantly differentially expressed proteins highlighted processes involved in metastasis. (A) String analysis of significantly differentially expressed proteins. Cluster analysis based on protein-protein interactions revealed 4 clusters. $(\mathbf{B}, \mathbf{C})$ Gene ontology enrichment analysis of significantly differentially expressed proteins highlighted several areas of ontology including extracellular space, cytoskeletal, vesicles and binding. GO; Gene ontology. CC; cell compartment. MF; molecular function. REAC; reactome.

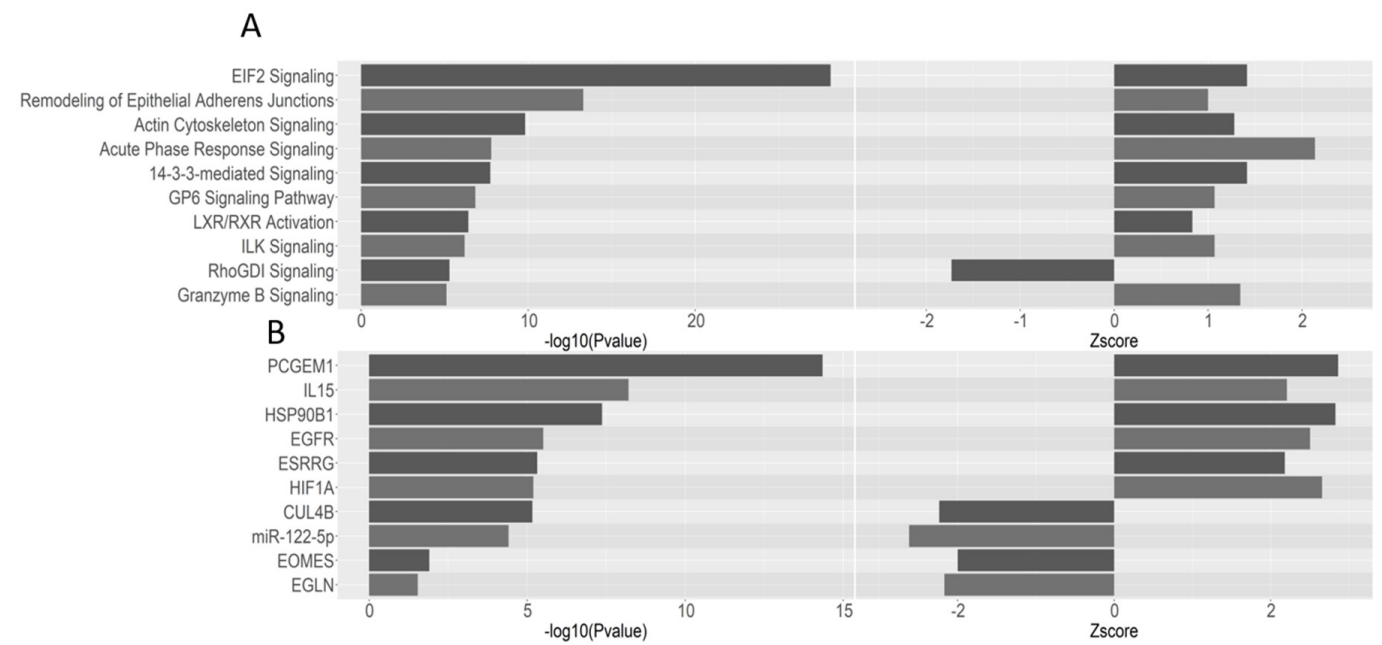

Figure 5. Ingenuity pathway analysis (IPA) of P-M vs. P-NM proteomics data. Unique protein IDs present in at least $50 \%$ of samples were analysed using IPA with fold changes and $p$ values used as metrics. (A) IPA pathway analysis. (B) IPA upstream regulator analysis. 


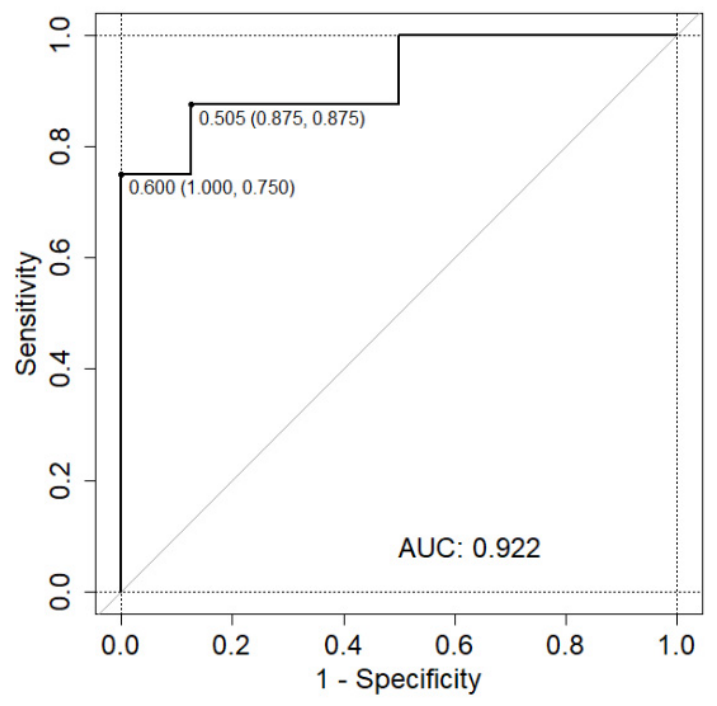

Figure 6. Machine learning on the proteomics data generated a model capable of predicting melanoma metastasis. Significantly differentially expressed proteins were trained on $67 \%$ of the data (32 melanoma samples) using 5-fold cross validation repeated 3 times. Missing values were median imputed. Several different algorithms were tested for performance by ROC analysis and then the best performing tested on the $33 \%$ of data held out for testing (16 melanoma samples).

\section{Discussion}

The majority of human primary tumours are excised where possible in order to minimise the development of subsequent metastases. The excised tissue is processed to produce FFPE samples, thus preserving the tissue and the tissue architecture to allow a diagnosis to be made, along with any additional immunohistochemistry investigations to support the diagnosis and possibly indicate prognoses. As this procedure is commonplace across many countries, the resulting samples represent an extremely large worldwide biobank of FFPE tissue pathology from a multitude of cancers and other non-neoplastic diseases [1]. Furthermore, complementary clinical information is often available, thus providing a valuable resource for studies looking for biomarkers, possible therapeutic targets, etc.

In this study, we utilised FFPE melanoma samples along with clinical information to perform a retrospective study on primary melanomas to identify proteins and pathways associated with the progression of melanoma to metastatic melanoma. Using a quantitative proteomic approach, we compared 24 FFPE primary melanomas that had metastasised (P-M) and 24 FFPE primary melanomas which had not metastasised (P-NM). Breslow depth is a well-known prognostic marker for cutaneous melanoma $[14,15]$, and, therefore, samples were stratified to ensure there was no significant difference in Breslow thickness between P-M and P-NM groups.

We identified 2750 proteins across the FFPE primary tumours and statistical analysis revealed 16 significantly differentially expressed proteins between P-M and P-NM (Figure 2). Several of these proteins were unable to be quantified across all 24 P-Ms and 24 P-NMs. This may be attributed to the complex nature of FFPE samples and the extensive number of cross-linkages formed during the fixation process. Cross-linked peptides will often result in a peptide not being matched to a protein because of unknown peptide modifications which are unaccounted for during the database search. Furthermore, these cross-linkages increase the complexity of the sample, which subsequently increases the signal: noise threshold [16]. Although many imputation methods exist, we considered the most conservative approach was to use the available data without imputation as it is often more robust and is less likely to suffer from any other biases [17]. Many of these 16 proteins have previously been shown to influence metastasis in other cancers, for instance, ACTG1 in liver cancer [18], Immunoglobulin heavy constant gamma 3 (IGHG3) in breast cancer [19], Proteasome subunit alpha type-1 (PSMA1) in colon cancer [20], Ras-related protein Rab-11A (RAB11a) in pancreatic cancer [21], PEBP1 and Eukaryotic translation 
elongation factor 1 alpha 1 (EEF1A1) in hepatocellular carcinoma [22,23], MYH9 in colorectal [24] and ovarian cancer [25], POSTN in melanoma [26], hepatocellular carcinoma [27] and breast cancer [28] and SND1 in breast cancer [29] and cervical cancer [30]. Furthermore, five of these proteins were identified as significantly differentially expressed between PM and PNMs in two NCBI GEO datasets and the gene expression of 6 of these 16 significantly differentially expressed proteins (i.e., EVPL, POSTN, KRT9, MYH9, MYH16 and PEBP1) each had a significant effect on 3-year survival rates in cutaneous melanoma as identified from the TCGA database. Interestingly, here we report that both protein and mRNA expression (via microarray) of KRT9 is significantly increased in PNMs compared to PMs but, when investigating mRNA (via RNAseq) in terms of survival, an increase in KRT9 is associated with poorer outcome.

STRING, GO and IPA of the proteomics data highlighted several key processes likely to be involved in melanoma metastasis. Translation and protein synthesis were identified by both gene ontology enrichment (Figure 4C) and pathway analysis (Figure 5A) and could be accredited to the loss of differentiation (and therefore a change in which proteins are produced and at what amounts) indicative of metastatic tumours [31,32]. Cell migration is also a key step in tumour progression and metastasis [33], occurring via a complex mechanism whereby the migrating cell remodels the cytoskeleton (Figure 4) to produce invadopodium which then break down the extracellular matrix to allow invasion into the surrounding tissue. A dysregulation of Rho signalling (Figure 5) is known to influence cell polarity and thus, in this instance, could be promoting progression by increasing invasiveness [34]. Furthermore, an activation of Epidermal growth factor receptor (EGFR) predicted by IPA and Epidermal growth factor (EGF) has been shown to promote invadopodium formation, aiding invasion and migration [35]. Additionally, an enrichment in intracellular vesicles, dense bodies and extracellular exosomes/organelles and vesicles were identified in GO (Figure 4C), suggesting possible extracellular trafficking. Related to this, it is known that tumour-derived exosomes can promote the development of metastasis from cancer, including from melanoma, in distant organs [36,37].

It is recognised that the immune system plays an important role in tumorigenesis and cancer metastases, including in skin cancer [38,39]. Indeed, it has been shown that immunosuppressed individuals have an increased risk of developing melanoma [40], and that immunosuppressed individuals are at much greater risk of developing metastasis than immunocompetent individuals [41]. In the current study, IPA revealed upregulation of IL15 signalling, an interleukin known to promote the activation and proliferation of natural killer cells and T cells [42,43]. Furthermore, the protein HSP90B1, which has been reported as playing a critical role in the regulation of natural killer and T cells [44] was predicted by IPA as an activated upstream regulator. In addition, an increase in granzyme B signalling (an important protease in the CD8+ cytotoxic T cells arsenal) was noted; however, IPA also indicated inhibition of signalling of eomesodermin (EOMES) which is also highly expressed in CD8+ T cells but seems to play a complex role in antitumour responses with some evidence for the promotion of adaptive immune responses against cancer but also in promoting CD8+ T cell exhaustion [45,46]. Furthermore, the aforementioned enrichment in extracellular trafficking may also involve the immune response, because recent evidence suggests that melanoma-derived exosomes can suppress effector cells in patients with this cancer [47].

Many studies in the published literature report on differences between benign/precancerous and primary and/or metastastic tumours; however, we took a different approach where we conducted proteomics on primary tumours which had metastasised and primary tumours that had not metastasised. As our study was performed on primary tumours, it presented the opportunity to investigate whether the significantly differentially expressed proteins could reliably be used to classify samples into either P-M or P-NM (i.e., metastasising or non-metastasising primary tumours). Using a Distance Weighted Discrimination with a Radial Basis Function Kernel machine learning model, an AUC of 0.922 was achieved suggesting these proteins as potential predictive protein biomarkers. Admittedly, these potential biomarkers will need to be investigated in a larger cohort to further assess their predictive 
power and utility. Nonetheless, access to the large valuable resource of FFPE tumours in healthcare opens up the opportunity for validating and identifying further prognostic biomarkers of melanoma.

This study has identified a number of proteins and pathways associated with the progression of melanoma to metastatic melanoma and has highlighted several potential biomarkers that could be further developed to predict the metastatic potential of primary melanomas from routinely collected FFPE samples.

\section{Materials and Methods}

\subsection{Tissue Samples}

FFPE human primary melanomas were acquired from Histopathology, University Hospital Southampton NHS Foundation Trust (UHS-NHSFT) under local research ethics committee approval (South Central Hampshire B National Research Ethics Service Committee; LREC number 07/H0504/187, amendment approved 7th July 2014). Samples were categorized as primary melanomas that metastasised (P-M) or primary melanomas that had not metastasised (P-NM), with the latter based on an absence of metastasis as determined by Dermatology UHS-NHSFT at and/or beyond 5-years post-surgical excision of the primary tumour. Samples were stratified for Breslow thickness so that there was no significant difference in this parameter between the two groups.

\subsection{Microdissection and Processing of FFPE Tumour Samples}

Three $10 \mu \mathrm{m}$ FFPE sections per sample were cut and mounted onto glass slides before being deparaffinised, rehydrated, and stained with Mayer's hematoxylin. The melanoma and associated immune infiltrate were microdissected and placed into $100 \mu \mathrm{L}$ protein extraction buffer (containing $50 \mathrm{mM}$ ammonium bicarbonate, $5 \mathrm{mM}$ dithiothreitol, and $0.2 \%$ RapiGest SF (Waters, UK)). Following heating at $105^{\circ} \mathrm{C}$ for $30 \mathrm{~min}$, samples were cooled on ice for $5 \mathrm{~min}$, re-heated to $80^{\circ} \mathrm{C}$ for $2 \mathrm{~h}$, placed on ice for $5 \mathrm{~min}$ again before reduction using $5 \mathrm{mM}$ dithioerythritol at $60^{\circ} \mathrm{C}$ for $30 \mathrm{~min}$. To alkylate the samples, a final concentration of $15 \mathrm{mM}$ iodoacetamide was added to each sample and incubated for $30 \mathrm{~min}$, in the dark, at room temperature. Samples were subsequently digested overnight at $37^{\circ} \mathrm{C}$ with $1 \mu \mathrm{g}$ trypsin. To cleave the Rapigest, a final concentration of $0.5 \%$ TFA was added to each sample and incubated at $37^{\circ} \mathrm{C}$ for $30 \mathrm{~min}$. Samples were next centrifuged at $15,000 \times g$ for $15 \mathrm{~min}$. Supernatants were collected and lyophilised using an Eppendorf Concentrator-5301, then reconstituted in $150 \mu \mathrm{L}$ of buffer A ( $0.5 \%$ formic acid in LC/MS grade water). C18 reverse phase clean-up was performed on the digested peptides using an EmporeTM C18 plate (Sigma, Poole, UK), where samples were bound to the membrane and washed twice with buffer A, before being eluted with $80 \%$ acetonitrile/water. Samples were subsequently lyophilised and reconstituted in buffer A ready for mass spectrometry analysis.

\subsection{Liquid Chromatography Mass Spectrometry $\left(L C-M S^{E}\right)$}

Samples were analysed using a nanoACQUITY UPLC system (Waters, Manchester, UK) coupled to a Synapt G2-Si high-resolution mass spectrometer (Waters, UK) operating in MSE mode with ion mobility enabled. Peptide extracts were trapped onto a Symmetry-C18 $180 \mu \mathrm{m}$ x $20 \mathrm{~mm}$ trap column (Waters, UK) using buffer A and subsequently separated on a $75 \mu \mathrm{m}$ I.D x $250 \mathrm{~mm}, 1.7 \mu \mathrm{m}$ particle size, C18 analytical column (Waters, UK) over a 150-min linear gradient of 1 to $65 \%$ of buffer B $(0.1 \%$ formic acid in acetonitrile $(v / v))$. A constant flow rate of $300 \mathrm{nl} / \mathrm{min}$ was used and $20 \mu \mathrm{L} / \mathrm{min}$ for trapping. Samples were introduced into the mass spectrometer using electrospray ionisation. Three, one-hour blank gradients between each sample were performed to eliminate carryover between samples. Samples were randomly batched into groups of 12 . Standards were analysed at the beginning and end of every batch to assess instrument performance. Raw mass spectrometry data were processed using ProteinLynx Global Server 3.0 (Waters, UK) and searched against the human SwissProt database (November 2016 - 20,214 entries) allowing for deamidation of asparagine and glutamine, oxidation of 
methionine, and hydroxymethylation of cysteine with fixed modifications of carbamidomethylation of cysteine. The false discovery rate (FDR) was estimated with randomized decoy database searches and was filtered to $1 \%$ FDR at the protein level.

\subsection{Data and Statistical Analysis}

Only proteins detected in $\geq 50 \%$ of samples were subsequently analysed. Protein concentrations were normalised to median protein concentration for each sample. Volcano plots were created using $\mathrm{R}$, Version 3.5.0. $p$ values were calculated using Mann-Whitney $U$ test for significance. Inferno RDN V1.1.7 was used to perform statistical analysis on proteomics data. R packages caret, pROC and doParallel were utilised for machine learning. The open source $R$ package, gprofiler2 ver0.1.8 was used for gene ontology analysis and pathway analysis was performed using Ingenuity pathway analysis (IPA) with the results exported to create graphs in R.

\subsection{NCBI GEO and TCGA Analysis}

NCBI GEO datasets GSE15605 and GSE46517 were downloaded using the GEOquery (ver 2.58.0) package in R. Primary melanomas were extracted from the expression data and sorted into PM and PNM using the metadata provided. Patients in GSE46517 that were identified as having other cancers or those which died from unrelated reasons, were removed. Repeat gene probes were mean averaged. $\mathrm{T}$ test and Wilcoxon signed rank tests were performed depending on the data's gaussian distribution. Plots were made in GraphPad prism. Using the FirebrowseR package for R (ver 1.1.35) and the Firebrowse webpage, TCGA clinical and gene expression data were obtained for the 16 significantly differentially expressed proteins identified between P-M and P-NM. The RSEM scaled estimate gene expression output was multiplied by 1^106 to calculate the transcripts per million, which was then used to plot survival curves. Survival data of 3 years were plotted in $\mathrm{R}$ using the Survminer and Survival packages. The optimal cut point for each group was calculated using the Survminer package which utilizes the maximally selected rank statistics from the maxstat $\mathrm{R}$ package.

\subsection{Machine Learning}

Proteomic data were split into training and test datasets, consisting of $67 \%$ [32] and 33\% [16], respectively. Machine learning was performed on the training set using 5 -fold cross validation repeated 3 times. For the 16 significantly differentially expressed proteins, a Distance Weighted Discrimination with a Radial Basis Function Kernel model was employed. Each resample was tuned using automatic tuning with a maximum tune length of 50 .

Author Contributions: Conceptualization, E.H. and P.S.; Data curation, C.L.; Formal analysis, A.S.; Funding acquisition, E.H. and P.S.; Investigation, A.S.; Methodology, A.S. and E.P.; Resources, C.L., M.S. and P.S.; Software, A.S.; Supervision, E.H. and P.S.; Validation, A.S.; Visualization, A.S.; Writing-original draft, A.S. and P.S.; Writing - review and editing, A.S., E.H. and P.S. All authors have read and agreed to the published version of the manuscript.

Funding: Instrumentation in the Centre for Proteomic Research is supported by the BBSRC (BM/M012387/1) and Wessex Medical Trust. AS was supported by the Wessex Medical trust. AS and PS were also supported by the charity Against Breast Cancer.

Conflicts of Interest: The authors declare no conflict of interest. 


\section{Abbreviations}

$\begin{array}{ll}\text { AUC } & \text { Area under the curve } \\ \text { FFPE } & \text { Formalin fixed, paraffin embedded } \\ \text { FDR } & \text { False discovery rate } \\ \text { GO } & \text { Gene ontology } \\ \text { IPA } & \text { Ingenuity pathway analysis } \\ \text { LC-MS } & \text { Liquid chromatography - mass spectrometry } \\ \text { P-M } & \text { Primary metastatic } \\ \text { P-NM } & \text { Primary non-metastatic } \\ \text { ROC } & \text { Receiver operating characteristic curve } \\ \text { TCGA } & \text { The Cancer Genome Atlas }\end{array}$

\section{References}

1. Wisniewski, J.R. Proteomic sample preparation from formalin fixed and paraffin embedded tissue. J. Vis. Exp. 2013, 79, 50589. [CrossRef] [PubMed]

2. Wisniewski, J.R.; Ostasiewicz, P.; Mann, M. High Recovery Fasp Applied to The Proteomic Analysis of Microdissected Formalin Fixed Paraffin Embedded Cancer Tissues Retrieves Known Colon Cancer Markers. J. Proteome. Res. 2011, 10, 304-309. [CrossRef] [PubMed]

3. Dapic, I.; Baljeu-Neuman, L.; Uwugiaren, N.; Kers, J.; Goodlett, D.R.; Corthals, G.L. Proteome Analysis of Tissues by Mass Spectrometry. Mass. Spectrom. Rev. 2019, 38, 403-441. [CrossRef] [PubMed]

4. Schadendorf, D.; van, A.; Alexander, C.J.; Berking, C.; Griewank, K.G.; Gutzmer, R.; Hauschild, A.; Stang, A.; Roesch, A.; Ugurel, S. Melanoma. Lancet 2018, 392, 971-984. [CrossRef]

5. GLOBOCAN. GLOBOCAN 2017. Available online: http://globocan.iarc.fr/Default.aspx (accessed on 1 September 2019).

6. Kalady, M.F.; White, R.R.; Johnson, J.L.; Tyler, D.S.; Seigler, H.F. Thin Melanomas: Predictive Lethal Characteristics from A 30-Year Clinical Experience. Ann. Surg. 2003, 238, 528. [CrossRef]

7. Sandru, A.; Voinea, S.; Panaitescu, E.; Blidaru, A. Survival Rates of Patients with Metastatic Malignant Melanoma. J. Med. Life 2014, 7, 572.

8. Meier, F.; Will, S.; Ellwanger, U.; Schlagenhauff, B.; Schittek, B.; Rassner, G.; Garbe, C. Metastatic Pathways and Time Courses in The Orderly Progression of Cutaneous Melanoma. Br. J. Dermatol. 2002, 147, 62-70. [CrossRef]

9. Siegel, R.L.; Miller, K.D.; Jemal, A. Cancer Statistics, 2016. CA Cancer J Clin. 2016, 66, 7-30. [CrossRef]

10. Eggermont, A.M.M.; Spatz, A.; Robert, C. Cutaneous Melanoma. Lancet 2014, 383, 816-827. [CrossRef]

11. Dowling, P.; Moran, B.; McAuley, E.; Meleady, P.; Henry, M.; Clynes, M.; McMenamin, M.; Leonard, N.; Monks, M.; Wynne, B.; et al. Quantitative Label-Free Mass Spectrometry Analysis of Formalin-Fixed, Paraffin-Embedded Tissue Representing The Invasive Cutaneous Malignant Melanoma Proteome. Oncol. Lett. 2016, 12, 3296-3304. [CrossRef]

12. Byrum, S.; Avaritt, N.L.; Mackintosh, S.G.; Munkberg, J.M.; Badgwell, B.D.; Cheung, W.L.; Tackett, A.J. A quantitative proteomic analysis of FFPE melanoma. J. Cutan. Pathol. 2011, 38, 933. [CrossRef] [PubMed]

13. Byrum, S.D.; Larson, S.K.; Avaritt, N.L.; Moreland, L.E.; Mackintosh, S.G.; Cheung, W.L.; Tackett, A.J. Quantitative Proteomics Identifies Activation of Hallmark Pathways of Cancer in Patient Melanoma. J. Proteom. Bioinform. 2013, 6, 43-50. [CrossRef] [PubMed]

14. Ge, L.; Vilain, R.E.; Lo, S.; Aivazian, K.; Scolyer, R.A.; Thompson, J.F. Breslow Thickness Measurements of Melanomas Around American Joint Committee on Cancer Staging Cut-Off Points: Imprecision and Terminal Digit Bias Have Important Implications for Staging and Patient Management. Ann. Surg. Oncol. 2016, 23, 2658-2663. [CrossRef]

15. Breslow, A. Thickness, Cross-Sectional Areas and Depth of Invasion in The Prognosis of Cutaneous Melanoma. Ann. Surg. 1970, 172, 902. [CrossRef]

16. Bantscheff, M.; Lemeer, S.; Savitski, M.M.; Kuster, B. Quantitative Mass Spectrometry in Proteomics: Critical Review Update from 2007 to The Present. Anal. Bioanal. Chem. 2012, 404, 939-965. [CrossRef]

17. Webb-Robertson, B.J.; Wiberg, H.K.; Matzke, M.M.; Brown, J.N.; Wang, J.; Mcdermott, J.E.; Smith, R.D.; Rodland, K.D.; Metz, T.O.; Pounds, J.G.; et al. Review, Evaluation, and Discussion of The Challenges of 
Missing Value Imputation for Mass Spectrometry-Based Label-Free Global Proteomics. J. Proteome. Res. 2015, 14, 1993-2001. [CrossRef] [PubMed]

18. Liu, J.; Zhong, X.; Li, J.; Liu, B.; Guo, S.; Chen, J.; Tan, Q.; Wang, Q.; Ma, W.; Wu, Z.; et al. Screening and Identification of Lung Cancer Metastasis-Related Genes by Suppression Subtractive Hybridization. Thorac. Cancer 2012, 3, 207-216. [CrossRef]

19. Hsu, H.-M.; Chu, C.-M.; Chang, Y.-J.; Yu, J.-C.; Chen, C.-T.; Jian, C.-E.; Lee, C.-Y.; Yueh, C.-T.; Chi, W.C.; Chang, Y.-T. Six Novel Immunoglobulin Genes as Biomarkers for Better Prognosis in Triple-Negative Breast Cancer by Gene Co-Expression Network Analysis. Sci. Rep. 2019, 9, 4484. [CrossRef]

20. Yang, Q.; Roehrl, M.H.; Wang, J.Y. Proteomic Profiling of Antibody-Inducing Immunogens in Tumor Tissue Identifies PSMA1, LAP3, ANXA3, and Maspin as Colon Cancer Markers. Oncotarget 2017, 9, 3996-4019. [CrossRef]

21. Yu, L.; Li, X.; Li, H.; Chen, H.; Liu, H. Rab11a Sustains GSK3beta/Wnt/Beta-Catenin Signaling to Enhance Cancer Progression in Pancreatic Cancer. Tumour. Biol. J. Int. Soc. Oncodevelopmental Biol. Med. 2016, 37, 13821. [CrossRef]

22. Xu, Y.F.; Yi, Y.; Qiu, S.J.; Gao, Q.; Li, Y.W.; Dai, C.X.; Cai, M.-Y.; Ju, M.-J.; Zhou, J.; Zhang, B.-H.; et al. PEBP1 Downregulation Is Associated to Poor Prognosis in HCC Related to Hepatitis B Infection. J. Hepatol. 2010, 53, 872-879. [CrossRef] [PubMed]

23. Chen, S.L.; Lu, S.X.; Liu, L.L.; Wang, C.H.; Yang, X.; Zhang, Z.Y.; Zhang, H.-Z.; Yun, J.-p. eEF1A1 Overexpression Enhances Tumor Progression and Indicates Poor Prognosis in Hepatocellular Carcinoma. Transl. Oncol. 2018, 11, 125-131. [CrossRef] [PubMed]

24. Wang, B.; Qi, X.; Liu, J.; Zhou, R.; Lin, C.; Shangguan, J.; Hang, Z.; Zhao, L.; Li, G. MYH9 Promotes Growth and Metastasis via Activation of MAPK/AKT Signaling in Colorectal Cancer. J. Cancer. 2019, 10, 874. [CrossRef]

25. Liu, L.; Yi, J.; Deng, X.; Yuan, J.; Zhou, B.; Lin, Z.; Zeng, Z. MYH9 Overexpression Correlates with Clinicopathological Parameters and Poor Prognosis of Epithelial Ovarian Cancer. Oncol. Lett. 2019, 18, 1049-1056. [CrossRef]

26. Fukuda, K.; Sugihara, E.; Ohta, S.; Izuhara, K.; Funakoshi, T.; Amagai, M.; Saya, S. Periostin Is a Key Niche Component for Wound Metastasis of Melanoma. PLoS ONE. 2015, 10, e0129704. [CrossRef]

27. Wen, Q.; Shang, J.; Mise, S.R.L.; Bai, L. Effects of Periostin on Hepatocellular Carcinoma Cells Invasion, Metastasis and Prognosis. Chin. J. Hepatol. 2019, 27, 766-771.

28. Wang, Z.; Xiong, S.; Mao, Y.; Chen, M.; Ma, X.; Zhou, X.; Ma, Z.; Liu, F.; Huang, Z.; Luo, Q.; et al. Periostin Promotes Immunosuppressive Premetastatic Niche Formation to Facilitate Breast Tumour Metastasis. J. Pathol. 2016, 239, 484-495. [CrossRef]

29. Yu, L.; Liu, X.; Cui, K.; Di, Y.; Xin, L.; Sun, X.; Zhang, W.; Yang, X.; Wei, M.; Yao, Z.; et al. SND1 Acts Downstream of TGFbeta1 and Upstream of Smurf1 to Promote Breast Cancer Metastasis. Cancer Res. 2015, 75, 1275-1286. [CrossRef]

30. Zhan, F.; Zhong, Y.; Qin, Y.; Li, L.; Wu, W.; Yao, M. SND1 Facilitates The Invasion and Migration of Cervical Cancer Cells by Smurf1-Mediated Degradation of FOXA2. Exp. Cell Res. 2019, 388, 111809. [CrossRef] [PubMed]

31. Agaimy, A.; Specht, K.; Stoehr, R.; Lorey, T.; Märkl, B.; Niedobitek, G.; Straub, M.; Hager, T.; Reis, A.-C.; Schilling, B.; et al. Metastatic Malignant Melanoma with Complete Loss of Differentiation Markers (Undifferentiated/Dedifferentiated Melanoma). Am. J. Surg. Pathol. 2016, 40, 181-191. [CrossRef]

32. Ruggero, D. Translational Control in Cancer Etiology. Cold Spring Harb. Perspect. Biol. 2013, 5, a012336. [CrossRef] [PubMed]

33. Yamaguchi, H.; Wyckoff, J.; Condeelis, J. Cell Migration in Tumors. Curr. Opin. Cell Biol. 2005, 17, $559-564$. [CrossRef]

34. Ellenbroek, S.I.; Collard, J.G. Rho GTPases: Functions and Association with Cancer. Clin. Exp. Metastasis. 2007, 24, 657-672. [CrossRef] [PubMed]

35. Yamaguchi, H.; Lorenz, M.; Kempiak, S.; Sarmiento, C.; Coniglio, S.; Symons, M.; Segall, J.; Eddy, R.; Miki, H.; Takenawa, T.; et al. Molecular Mechanisms of Invadopodium Formation: The Role of the N-WASP-Arp2/3 Complex Pathway and Cofilin. J. Cell Biol. 2005, 168, 441-452. [CrossRef]

36. Gowda, R.; Robertson, B.M.; Iyer, S.; Barry, J.; Dinavahi, S.S.; Robertson, G.P. The Role of Exosomes in Metastasis and Progression of Melanoma. Cancer Treat. Rev. 2020, 85, 101975. [CrossRef] 
37. Wu, M.; Wang, G.; Hu, W.; Yao, Y.; Yu, X.-F. Emerging Roles and Therapeutic Value of Exosomes in Cancer Metastasis. Mol. Cancer. 2019, 18, 53. [CrossRef] [PubMed]

38. Shapanis, A.; Lai, C.; Smith, S.; Coltart, G.; Sommerlad, M.; Schofield, J.; Parkinson, E.; Skipp, P.; Healy, E. Identification of proteins associated with development of metastasis from cutaneous squamous cell carcinomas (cSCCs) via proteomic analysis of primary cSCCs. Br. J. Dermatol. 2020. [CrossRef]

39. Lai, C.; August, S.; Albibas, A.; Behar, R.; Cho, S.Y.; Polak, M.E.; Theaker, J.; MacLeod, A.S.; French, R.R.; Glennie, M.J. OX40+ Regulatory T Cells in Cutaneous Squamous Cell Carcinoma Suppress Effector T-Cell Responses and Associate with Metastatic Potential. Clin. cancer Res. 2016, 22, 4236-4248. [CrossRef]

40. Euvrard, S.; Kanitakis, J.; Claudy, A. Skin Cancers after Organ Transplantation. N. Engl. J. Med. 2003, 348, 1681-1691. [CrossRef]

41. Martinez, J.C.; Otley, C.C.; Stasko, T.; Euvrard, S.; Brown, C.; Schanbacher, C.F.; Weaver, A.L. Defining the Clinical Course of Metastatic Skin Cancer in Organ Transplant Recipients: A Multicenter Collaborative Study. Arch. Dermatol. 2003, 139, 301-306. [CrossRef]

42. Dubois, S.; Conlon, K.C.; Müller, J.R.; Hsu-Albert, J.; Beltran, N.; Bryant, B.R.; Waldmann, T.A. IL15 Infusion of Cancer Patients Expands The Subpopulation of Cytotoxic CD56bright NK Cells and Increases NK-Cell Cytokine Release Capabilities. Cancer Immunol. Res. 2017, 5, 929-938. [CrossRef] [PubMed]

43. Waldmann, T.A. The Biology of Interleukin-2 and Interleukin-15: Implications for Cancer Therapy and Vaccine Design. Nat. Rev. Immunol. 2006, 6, 595-601. [CrossRef]

44. Bae, J.; Munshi, A.; Li, C.; Samur, M.; Prabhala, R.; Mitsiades, C.; Anderson, K.C.; Munshi, N.C. Heat shock protein 90 is critical for regulation of phenotype and functional activity of human T lymphocytes and NK cells. J. Immunol. 2013, 190, 1360-1371. [CrossRef] [PubMed]

45. Zhu, Y.; Ju, S.; Chen, E.; Dai, S.; Li, C.; Morel, P.; Liu, L.; Zhang, X.; Lu, B. T-Bet and Eomesodermin are Required for T Cell-Mediated Antitumor Immune Responses. J. Immunol. 2010, 185, 3174-3183. [CrossRef]

46. Li, J.; He, Y.; Hao, J.; Ni, L.; Dong, C. High Levels of Eomes Promote Exhaustion of Anti-Tumor CD8(+) T Cells. Front. Immunol. 2018, 9, 2981. [CrossRef] [PubMed]

47. Sharma, P.; Diergaarde, B.; Ferrone, S.; Kirkwood, J.M.; Whiteside, T.L. Melanoma Cell-Derived Exosomes in Plasma of Melanoma Patients Suppress Functions of Immune Effector Cells. Sci. Rep. 2020, 10, 92. [CrossRef] [PubMed]

Publisher's Note: MDPI stays neutral with regard to jurisdictional claims in published maps and institutional affiliations.

(C) 2020 by the authors. Licensee MDPI, Basel, Switzerland. This article is an open access article distributed under the terms and conditions of the Creative Commons Attribution (CC BY) license (http://creativecommons.org/licenses/by/4.0/). 